\title{
Effect of repetitive firing on passive fit of metal substructure produced by the laser sintering in implant-supported fixed prosthesis
}

\author{
Musa Aykut Altintas ${ }^{1}$, Hakan Akin ${ }^{2 *}$ \\ ${ }^{1}$ Department of Prosthodontics, Faculty of Dentistry, Cumhuriyet University, Sivas, Turkey \\ ${ }^{2}$ Department of Prosthodontics, Faculty of Dentistry, Sakarya University, Sakarya, Turkey
}

\begin{abstract}
PURPOSE. The aim of the present study was to investigate the passive fit of metal substructure after repetitive firing processes in implant-supposed prosthesis. MATERIALS AND METHODS. Five implants $(4 \mathrm{~mm}$ diameter and $10 \mathrm{~mm}$ length) were placed into the resin-based mandibular model and 1-piece of screw-retained metal substructure was produced with the direct metal laser sintering (DMSL) method using Co-Cr compound $(n=10)$. The distance between the marked points on the multiunit supports and the marginal end of the substructure was measured using a scanning electron microscope (SEM) at each stage (metal, opaque, dentin, and glaze). 15 measurements were taken from each prosthesis, and 150 measurements from 10 samples were obtained. In total, 600 measurements were carried out at 4 stages. One-way ANOVA test was used for statistical evaluation of the data. RESULTS. When the obtained marginal range values were examined, differences between groups were found to be statistically significant $(P<.001)$. The lowest values were found in the metal stage $(172.4 \pm 76.5 \mu \mathrm{m})$ and the highest values $(238.03 \pm 118.92 \mu \mathrm{m})$ were determined after glaze application. When the interval values for groups are compared with pairs, the differences between metal with dentin, metal with glaze, opaque with dentin, opaque with glaze, and dentin with glaze were found to be significant $(P<.05)$, whereas the difference between opaque with metal was found to be insignificant $(P=.992)$. CONCLUSION. Passive fit of 1-piece designed implant-retained fixed prosthesis that is supported by multiple implants is negatively affected by repetitive firing processes. [J Adv Prosthodont 2020;12:167-72]
\end{abstract}

KEYWORDS: Implant; Fixed prosthesis; Passive fit; Laser sintering; Repetitive firing

\section{INTRODUCTION}

Two types of retention are used in implant-supported fixed prostheses: cemented or screw-retained prostheses. ${ }^{1,2}$ In both types, passive fit must always be provided. No tension of any kind should be observed when placing the prosthesis. These tension stresses that occur on the prosthesis can cause various complications. Screw loosening, screw frac-

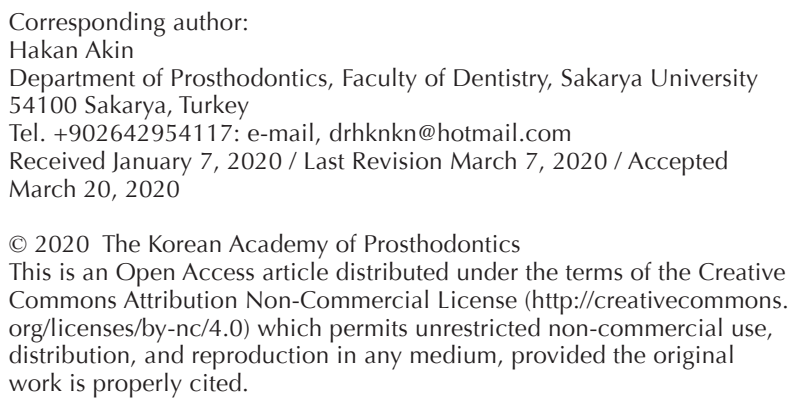

tures, and fractures of other parts of the system are confronted as mechanical complications; undesirable soft and hard tissue reactions, marginal bone loss, and failures in osseointegration can be confronted as biological complications. $^{3-6}$ The fabrication of prostheses with passive screw retention is more difficult than the fabrication of prostheses with cement retention. A nonpassive and improperly placed prosthesis with screw retainers may cause distortion on the superstructure while the prosthetic screw is being tightened and placed in its place. Distortion of the superstructure may cause bone loss by causing a focused tension in the crestal bone. A more passive placement of the implant abutment and more control of the occlusal loads in the prosthesis with screw retainer ensures longer life to the screw. ${ }^{4}$

It is important to obtain passive fit in fixed prostheses that are planned as a single piece supported by multiple implants. However, obtaining passive fit of the infrastructure through the traditional way of casting is hard to achieve. For this reason, alternative production methods are 
preferred. Among the most commonly used of these alternatives are computer-aided design and computer-aided manufacturing (CAD/CAM) techniques. ${ }^{7}$ Production is being done with the CAD/CAM technique and laser-sintering technique. ${ }^{8}$ According to the American Society for Testing and Materials, the selective laser-sintering technique is a layer-layer production system that combines the materials with the inverse production of 3-dimensional data. Production begins with the preparation of 3-dimensional computer files that are formed into a series of layers. Each layer is then overlapped to produce a 3-dimensional object, and production is carried out with the help of a printer. In the studies comparing the various production techniques used in the production of metal substructures, when the mechanical properties of the metal substructures and the porcelain connections are examined, it is stated that the metal substructures produced by laser sintering have better mechanical properties and that the bond strengths with porcelain are similar to the casting group. In addition, metal infrastructure production using laser sintering has stated advantages such as being more compatible, preparing more restorations per unit of time, lowering production cost, and producing fine and complex geometries.

On the other hand, feldspatic porcelain application is made to provide the desired aesthetics on the metal infrastructure and to mimic the optical properties. In accordance with the manufacturer's instructions, the firing process was carried out using special porcelain ovens with temperatures between 900 and $1000^{\circ} \mathrm{C}$. Considering the polishing process called "glaze," the prosthesis must also be fired several times until it is ready to be delivered to the patient. ${ }^{10}$ However, in the literature, an insufficient number of studies have been done regarding the effect of repetitive firing on passive fit, regardless of production method.

The present study was aimed at investigating the effects of repetitive firing processes on the passive fit of metal substructures obtained by the direct metal laser sintering (DMSL) method in screw-retained implant-supported fixed prosthesis. In addition, the hypothesis that repetitive firing processes have no negative effect on the passive fit of metal substructures produced by the DMLS method was tested.

\section{MATERIALS AND METHODS}

In the present study, first, a resin-based acrylic jaw that mimics the mandibular jaw was produced using a 3D printer and a special software program by MegaGen (MegaGen Implant, Seoul, Korea). In addition, the acrylic jaw was coated with 2-mm-thick, pink-colored elastomeric silicone to imitate the gingiva.

To be able to place the implants at the right angle and parallel to each other, a special surgical stent was produced with MegaGen's R2gate system (MegaGen, Korea). Five implants were placed parallel to the resin-based acrylic jaw. Dental implants with a $4 \mathrm{~mm}$ diameter and a $10 \mathrm{~mm}$ length (AnyOne, MegaGen, Korea) were used as implant materials. They have internal hex connection and conical design with a special extra surface coating called Xpeed. This unique hydro-thermal incorporation of calcium ions has already been proven to activate osteoblasts and accelerate osseointegration. First, the prepared surgical stent was fixed to the resin-based acrylic jaw with mini screws. Five implants were placed in the acrylic jaw: 1 to the center of the central teeth, 2 in the anterior of the mental foramen, and 2 implants in the middle of the distance between the central implant and the distal implants. The implants were placed using the surgical stents as guides. The gaps where the implants were to be placed were opened via a physiodispenser (MegEngine, MegaGen, Korea) at $800 \mathrm{rpm}$. While opening the implant cavities, the cooling serum was not used physiologically. The implants were placed into openings at $25 \mathrm{rpm}$ with the help of the physiodispenser. To be able to place the implants at the desired level into the jaw, according to the manufacturer's instructions, a surgical torque wrench was used to apply 30-60 N torque force to the placement provided in the resin-based acrylic jaws (Fig. 1A, 1B).

Specially produced, 13-mm scan abutments (MegaGen, Korea), developed by the manufacturer for use in digital measurement technique, were used (Fig. 1C). A 3D intraoral scanner was used for the measurement (Dental Wings 7 Series, DENTAL WINGS, Montreal, QC, Canada).

Prostheses were designed in such a way that the distance between the bone and the occlusal plane was $12 \mathrm{~mm}$. Of this distance, $7 \mathrm{~mm}$ was adjusted to be metal substructure, and $2 \mathrm{~mm}$ was adjusted to be feldspatic porcelain. Ten metal substructures with screw retention were obtained from Co-Cr alloy (Bego, Bremen, Germany) by using a laser-sintering device (M270, EOS, Munich, Germany) with the DMSL method (Fig. 2).

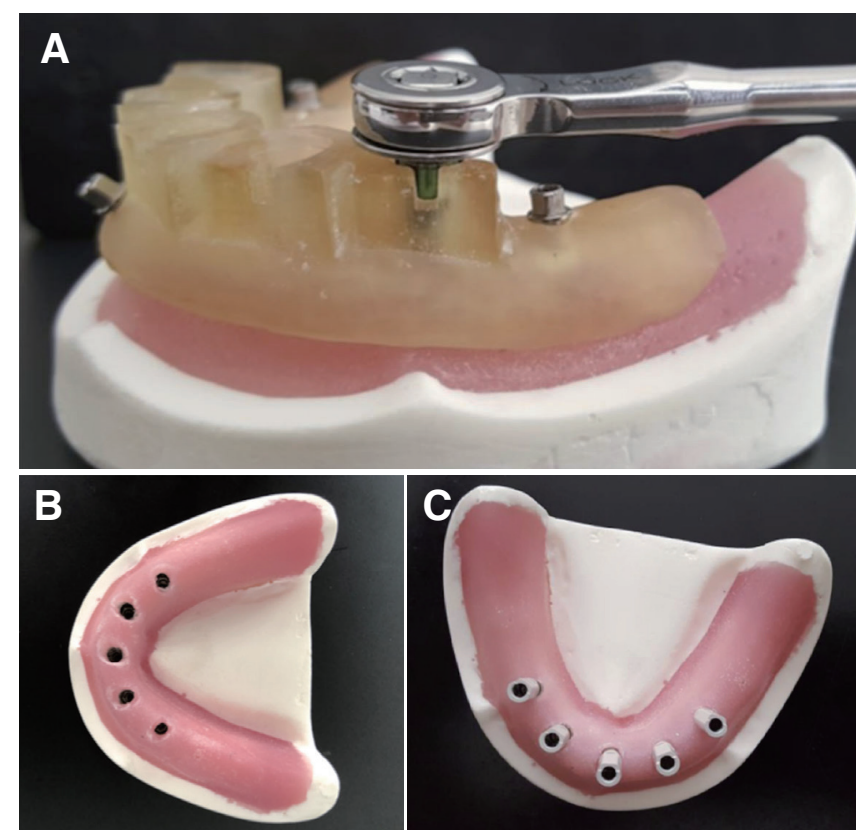

Fig. 1. (A) Green color was seen through the surgical guide while implant placement by torque wrench, (B) Implants were placed into the acrylic jaw, (C) Scan abutments were positioned on the implants. 


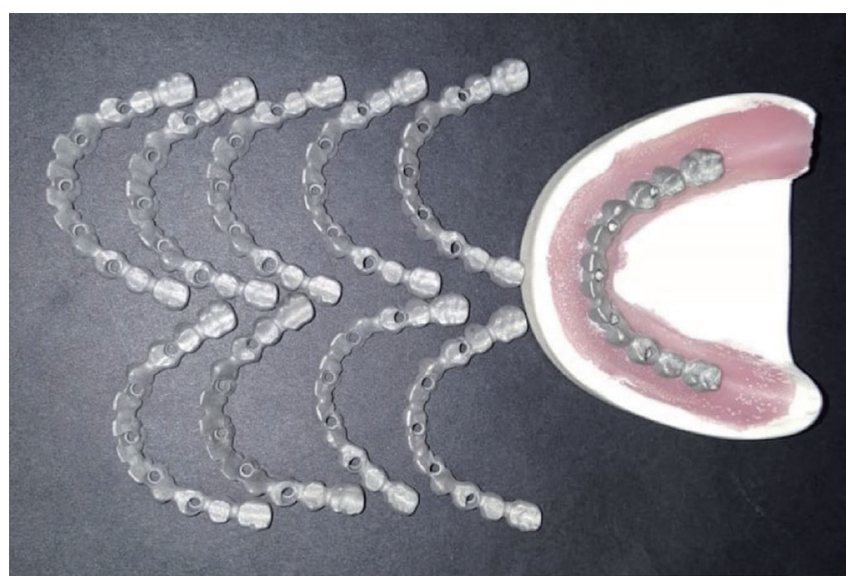

Fig. 2. Metal substructures were obtained from Co-Cr alloy with DMSL method.

The present study design was exhibited in the flowchart (Fig. 3). Metal substructures produced and obtained by the DMLS method, in accordance with the manufacturer's instructions, were subjected to flat multiunit abutments, which were tightened to implants by $25 \mathrm{~N}$ and torqued to $15 \mathrm{~N}$. Tightening the screws were performed in the following sequence: right anterior, left anterior, central, right distal, and left distal. Then metal substructures were examined using an SEM. The distance values between the marginal end of the prosthesis, which is designed, and the points created with the help of an aerator and diamond drills in the abutment were measured using the SEM device (TESCAN MIRA3 XMU, Brno, Czech Republic). Three measurements were performed on three different points (one of them is abutment finish line) for each abutment. Thus, 15 points were marked on 5 abutments. During the measurement, a special apparatus was produced that allowed the model to fit into the tray and remain fixed in the tray (Fig. 4). The apparatus that was fixed to the model before the measurements started in the metal phase was not removed from the model until the measurements were completed in the glaze phase. Thus, during the measurements, standard position in all stages was provided.

A total of 10 metal substructure produced by the DMLS method were fired in a ceramic oven without vacuum for 5 min at $960^{\circ} \mathrm{C}$ in accordance with the manufacturer's recommendation (Programat P310, IvoclarVivadent, Schaan, Liechtenstein). The same oven was used in all other firing applications.

After oxidation process, according to the manufacturer's instructions, steam was applied to the substructures, first under running water and then steam cleaning. The opaque powder and liquid (VITA, Vita VMK Master, Bad Sackingen, Germany) for the first layer were mixed in a glass and sprayed on to the metal substructure. After this application, the substructure was kept in a $500^{\circ} \mathrm{C}$ oven for $2 \mathrm{~min}$ for predrying, then the temperature was raised at an increase of $80^{\circ} \mathrm{C}$ per minute to $918^{\circ} \mathrm{C}$, and at this temperature it waited under vacuum for $1 \mathrm{~min}$. The same steps were repeated for

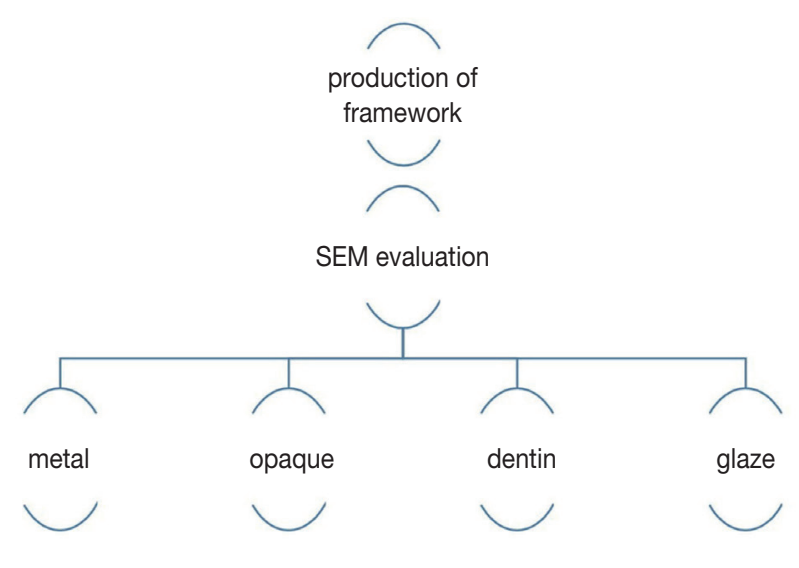

Fig. 3. Flowchart of the study.



Fig. 4. A special apparatus was attached to the jaw model for SEM analysis.

the second coat, but the temperature was increased until it reached $909^{\circ} \mathrm{C}$. Afterwards, for the metal substructures whose opaque application process was finished, the distance between the fixed points determined at the abutment with the marginal line was measured using the SEM device.

Then, $2 \mathrm{~mm}$ thick feldspatic porcelain was applied to all opaque porcelain samples according to their dental anatomy. Porcelain application was done with a brush using the stacking method. Using Vita VMK Master Dentin Powder (VITA, Germany) according to the manufacturer's recommendations, after predrying at $500^{\circ} \mathrm{C}$ for $6 \mathrm{~min}$, firing was done at $908^{\circ} \mathrm{C}$ after increasing the temperature by $55^{\circ} \mathrm{C}$ per minute. During the application of porcelain, all samples were prepared by the same technician at the same time to ensure standardization. At the same time, an equal amount of porcelain powder was used for each prosthesis (13.7 g), and a digital caliper was used to check both metal and porcelain thicknesses. After these procedures, the space between the marginal limits of the prosthesis was remeasured and fixed points were determined at the abutment using the SEM device. The obtained results were noted and glaze, the last 
process of the veneering phase, was applied.

All of the surfaces except the screw hole were covered with Vitaakzent (VITA, Germany) glaze. In accordance with the manufacturer's recommendations, after 4 minutes of predrying at $500^{\circ} \mathrm{C}$, glaze was applied at $855^{\circ} \mathrm{C}$ to increase the temperature by $80^{\circ} \mathrm{C}$ per minute. By using the SEM device, after the glaze-application process, measurements were repeated at the marginal line of the prosthesis. For all stages (metal, opaque, dentin, and glaze), all measurements were taken at the same points of the abutment and prosthesis (Fig. 5). The obtained results were noted.

In evaluating the data, the program IBM SPSS Statistics 22 (IBM SPSS, New York, NY, USA) was used for statistical analysis. Since the assumptions for a parametric test (Kolmogorov-Smirnov) were fulfilled, one-way analysis of variance was used to compare the means obtained from more than two independent groups. Tukey tests were used to find the differences between the groups. The data are stated as the mean and standard deviation at the table, and an error level of 0.05 was used.

\section{RESULTS}

The marginal distance averages and standard deviation (SD) values between the predefined fixed points on the main model's abutments and the marginal line of the prosthesis are calculated and shown in Table 1 . The substructures were grouped as metal, opaque, dentin, and glaze. While the lowest value was found in the metal group $(172.4 \pm 76.5 \mu \mathrm{m})$, the highest value was found in the glaze group (238.03 \pm



Fig. 5. SEM figures. The shortest measurement point is abutment finish line and the others were marked by a bur (A) Metal, (B) Opaque, (C) Dentin, (D) Glaze.
Table 1. Marginal distance averages and standard deviation values

\begin{tabular}{lcccl}
\hline & $\begin{array}{c}\text { Number of } \\
\text { measurements }\end{array}$ & $\begin{array}{c}\text { Marginal gap } \\
\text { Values }(\mu \mathrm{m})\end{array}$ & $\begin{array}{c}\text { Standard } \\
\text { deviation }\end{array}$ & \\
\hline Metal & 150 & 172.4 & 76.5 & $\mathrm{~F}=16.338$ \\
Opaque & 150 & 175.42 & 77.2 & $\mathrm{P}=.001^{*}$ \\
Dentin & 150 & 207.18 & 94.62 & $\mathrm{df}=3$ \\
Glaze & 150 & 238.03 & 118.92 & \\
\hline
\end{tabular}

$118.92 \mu \mathrm{m})$. When the interval measurements of the groups were compared, the difference among the groups was found significant $(P<.001)$. When group pairs of interval values were compared, the differences between metal and dentin $(P=.007)$, metal and glaze $(P<.001)$, opaque and dentin $(P$ $=.018$, opaque and glaze $(P<.001)$, and dentin and glaze $(P$ $=.023)$ were all significant, but the difference between metal and opaque was not significant $(P=.992)$.

\section{DISCUSSION}

In the present study, when the veneering process was completed, the marginal gap value of the metal ceramic restorations increased at each firing stage. Therefore, passive fit was negatively affected. In light of the obtained data, the hypothesis that repetitive firing processes do not have a negative effect on the passive fit of metal infrastructures obtained by the DMLS method was rejected.

However, the mean values in the present study were well above the clinically accepted values $(100-150 \mu \mathrm{m}){ }^{11}$ This is because the fixed points previously determined on the abutment were at the apex of the abutment's cervical finish line. Areas on the abutment were marked, and measurements were made from these areas in order to repeat the measurements at each stage from the same point. Considering that the step boundary can go apical after the metal processes, the points required for the measurement were marked just below the step level, nearly $77 \mu \mathrm{m}$ and $100 \mu \mathrm{m}$. In conclusion, the measured distances between the abutment's step limit and the marginal line of the metal substructure and of the prosthesis in the opaque, dentin, and glaze phases were within the clinically accepted limits.

Moreover, in the present study, SD values are high. Each abutment has three different measurement points that have different distances from step level of the abutment. Thus, for each abutment, measurement values did not exhibit close values to each other. Therefore, this situation caused high SD values for all groups.

In the literature, studies on the effects of repetitive firing on substructures produced by laser sintering are limited. ${ }^{12,13}$ Consistent with the present study, Zeng et al. found values of $67 \mu \mathrm{m}, 71 \mu \mathrm{m}, 72 \mu \mathrm{m}$, and $73 \mu \mathrm{m}$ in metal substructures produced by the SLM method after the first, third, fifth, and seventh firings, respectively. However, they stated that although the marginal range increased, they could not find a 
statistically significant difference. ${ }^{12}$ In another similar study by Quante et al., ${ }^{13}$ the edge opening of metal substructures produced by the DMLS method was an average of $73-93$ $\mu \mathrm{m}$ before ceramic firing and between 90 and $99 \mu \mathrm{m}$ after firing. They reported that while the increase in marginal gap values after porcelain firing was not statistically significant, the compatibility of metal substructures produced by laser sintering was within the acceptable range. Within other studies in the literature, ${ }^{14,15}$ many reasons have been proposed for the increase in the marginal gap value of repetitive firings. For example, veneering is carried out at elevated temperatures, which may adversely affect the edge alignment of the metal substructure. The prosthesis may change place in the occlusal direction due to deformations that occur in the substructure during firing. Studies ${ }^{14,15}$ have pointed out causes of such deformations, such as the type of alloy, porcelain shrinkage, the difference in thermal expansion coefficient between porcelain and alloy, infrastructure design, stress that emerges during casting and finishing, the deformation of alloy at high temperature, an inability to support metal substructure during firing, metal oxide formation on the inner surface, and step type. In the present study, it is thought that using metal substructure with a one-piece screw retainer may adversely affect passive fit, as a result of repeated firings.

The literature review on the changes to metal substructure in repetitive firing showed that the researchers agreed on two issues. First, deformation most often occurs in the initial oxidation process, and lower levels of change occur in the porcelain firing cycles. Second, since the metal substructure has more than 1 wall, the distortions cannot be attributed to a single cause; rather, it is necessary to think in multidirectional ways. ${ }^{16}$ In the oxidation phase, which is when the variation in the marginal gap is the highest, the application of excessive heat may decrease the metal substructure's elastic resistance and can tend to deform plastic. This may cause the metal substructure to creep. ${ }^{17}$ Likewise, Schilingburg and Buchanan also reported an increase in the marginal gap after the oxidation process, which they explained by showing the oxide layer formed in the inner region of the metal substructure. ${ }^{18}$ In another study, Anusavice and DeHoff ${ }^{19}$ reported that deformation during the oxidation process caused the release of tension after applying high heat. In a different study, Campbell et al. ${ }^{20}$ investigated the compatibility of the casting by preparing the casting substructure with a single axial wall on a specially prepared abutment that mimicked a single wall of the full crown preparation. The study showed that the oxidation phase caused deformation. Similarly, Gemalmaz ${ }^{15}$ reported a significant dimensional change in the oxidation stage, as compared with the other porcelain firing stages. In another study, Ando et al. ${ }^{21}$ also supported this finding. In their study with gold alloy castings, Ando et al. reported that after oxidation, aperture values of up to $100-150 \mu \mathrm{m}$ were formed and that mismatch did not increase during subsequent porcelain-firing processes. However, different from these studies, when examining the effects of firing, Dederich et al. ${ }^{22}$ found values averaging 20 - $22 \mu \mathrm{m}$, which were lower than the values found in oth- er studies. Hamaguchi ${ }^{23}$ also expressed a different view that after the application of opaque, gingiva, and enamel porcelain, shrinkage only occurs in the new porcelain layer and not in the opaque layer. Therefore, he reported that no change will happen in the glazing phase since no further shrinkage will occur when the porcelain addition is finished. Another explanation for deformation during veneering is the thermal expansion differences between metal and porcelain. However, De Hoff and Anusavice ${ }^{24}$ evaluated the effects of coping design and the thermal contraction difference between metal and ceramic on marginal fit by finite element analysis and stated that the effect of thermal contraction was small and that the design was ineffective. In another study supporting the previous study, Anusavice and Carrol reported that the difference in thermal contraction is not the primary factor in misfit. ${ }^{24,25}$

Different production techniques and materials were used to obtain the metal substructures in the studies examining the passive, marginal, and internal fit of prosthetic superstructures prepared on implants and natural teeth. ${ }^{26-30}$ In the vast majority, laser sintering was the most ideal method for passive fit. Furthermore, another reason for the DMLS method frequently being preferred is because the produced metal substructures form a reliable connection with the veneer porcelain. ${ }^{9,31,32}$ In light of these data in the literature, because the passive, internal, and marginal compatibility of metal substructures obtained by laser sintering is better than those of other methods, the DMLS method was preferred for fabricating metal substructures in the present study.

The reliability of the intraoral scanner systems used in digital measurement has increased due to technological developments, and their reliability has been proven within the literature. ${ }^{33}$ In the present study, measurements were taken from the mandibular epoxy resin jaw in which implants were placed using digital measurement.

In the present study, the passive fit of the metal substructures with a retaining screw was negatively affected by repetitive firing. Therefore, it is recommended not to fire metal substructures. Instead, it can be recommended to use cement retainer to place the crowns on the screw-retained metal substructures, after being prepared as Toronto prostheses, placed on implants, and torqued. This approach is more appropriate in terms of the biomechanics of implants and prostheses.

\section{CONCLUSION}

The passive fit of screw-retained implant-supported metalceramic prostheses is negatively affected by repetitive firing procedures. While the negative effect of passive adjustment was at its lowest between metal and opaque, negative effect increased even more between the other stages.

\section{ORCID}

Musa Aykut Altintas bttps://orcid.org/0000-0001-7320-546X Hakan Akin https://orcid.org/0000-0002-4770-4297 


\section{REFERENCES}

1. Sailer I, Mühlemann S, Zwahlen M, Hämmerle CH, Schneider D. Cemented and screw-retained implant reconstructions: a systematic review of the survival and complication rates. Clin Oral Implants Res 2012;23:163-201.

2. Wittneben JG, Millen C, Brägger U. Clinical performance of screw- versus cement-retained fixed implant-supported reconstructions-a systematic review. Int J Oral Maxillofac Implants 2014;29:84-98.

3. Millen C, Brägger U, Wittneben JG. Influence of prosthesis type and retention mechanism on complications with fixed implant-supported prostheses: a systematic review applying multivariate analyses. Int J Oral Maxillofac Implants 2015;30: 110-24.

4. Yannikakis S, Prombonas A. Improving the fit of implant prosthetics: an in vitro study. Int J Oral Maxillofac Implants 2013;28:126-34.

5. Rungruanganunt P, Taylor T, Eckert SE, Karl M. The effect of static load on dental implant survival: a systematic review. Int J Oral Maxillofac Implants 2013;28:1218-25.

6. Al-Otaibi HN, Akeel RF. The effects of two torque values on the screw preload of implant-supported prostheses with passive fit or misfit. Int J Oral Maxillofac Implants 2014;29:105863.

7. Ucar Y, Akova T, Akyil MS, Brantley WA. Internal fit evaluation of crowns prepared using a new dental crown fabrication technique: laser-sintered Co-Cr crowns. J Prosthet Dent 2009; 102:253-9.

8. Witkowski S. CAM in dental technology. Quintessence Dent Technol 2005;128:169-84.

9. Wu L, Zhu H, Gai X, Wang Y. Evaluation of the mechanical properties and porcelain bond strength of cobalt-chromium dental alloy fabricated by selective laser melting. J Prosthet Dent 2014;111:51-5.

10. Shillingburg HT, Sather DA, Wilson EL, Cain JR, Mitchell DL, Blanco LJ, Kessler JC. Fundamentals of fixed prosthodontics. Illinois; Quintessence Publishing Company; 2010.

11. Colpani JT, Borba M, Della Bona A. Evaluation of marginal and internal fit of ceramic crown copings. Dent Mater 2013; 29:174-80.

12. Zeng L, Zhang Y, Liu Z, Wei B. Effects of repeated firing on the marginal accuracy of Co-Cr copings fabricated by selective laser melting. J Prosthet Dent 2015;113:135-9.

13. Quante K, Ludwig K, Kern M. Marginal and internal fit of metal-ceramic crowns fabricated with a new laser melting technology. Dent Mater 2008;24:1311-5.

14. Lakhani SA, Ercoli C, Moss ME, Graser GN, Tallents RH. Influence of cold working and thermal treatment on the fit of implant-supported metal-ceramic fixed partial dentures. J Prosthet Dent 2002;88:159-69.

15. Gemalmaz D, Berksun S, Kasapoğlu C, Alkumru HN. Distortion of metal-ceramic fixed partial dentures resulting from metal-conditioning firing. Quintessence Int 1996;27: 193-201.

16. Gemalmaz D, Alkumru HN. Marginal fit changes during porcelain firing cycles. J Prosthet Dent 1995;73:49-54.
17. Balkaya MC, Cinar A, Pamuk S. Influence of firing cycles on the margin distortion of 3 all-ceramic crown systems. J Prosthet Dent 2005;93:346-55.

18. Shillingburg HT Jr, Hobo S, Fisher DW. Preparation design and margin distortion in porcelain-fused-to-metal restorations. J Prosthet Dent 1973;29:276-84.

19. DeHoff PH, Anusavice KJ, Boyce RJ. Analysis of thermallyinduced stresses in porcelain-metal systems. J Dent Res 1983; 62:593-7.

20. Campbell SD, Sirakian A, Pelletier LB, Giordano RA. Effects of firing cycle and surface finishing on distortion of metal ceramic castings. J Prosthet Dent 1995;74:476-81.

21. Ando N, Hakamura K, Namiki T, Sugata T, Suzuki T, Moriyama K. Deformation of porcelain bonded gold alloys. J Jpn Soc Appar Mater 1972;13:237-48.

22. Dederich DN, Svare CW, Peterson LC, Turner KA. The effect of repeated firings on the margins of nonprecious ceramometals. J Prosthet Dent 1984;51:628-30.

23. Hamaguchi $\mathrm{H}$, Cacciatore A, Tueller VM. Marginal distortion of the porcelain- bonded-to-metal complete crown: an SEM study. J Prosthet Dent 1982;47:146-53.

24. DeHoff PH, Anusavice KJ. Effect of metal design on marginal distortion of metal-ceramic crowns. J Dent Res 1984;63: 1327-31.

25. Anusavice KJ, Carroll JE. Effect of incompatibility stress on the fit of metal-ceramic crowns. J Dent Res 1987;66:1341-5.

26. Harish V, Mohamed Ali SA, Jagadesan N, Mohamed I, Senthil S, Debasish B, Huda F, Priyanka. Evaluation of internal and marginal fit of two metal ceramic system - in vitro study. J Clin Diag Res 2014;8:53-6.

27. Pompa G, Di Carlo S, De Angelis F, Cristalli MP, Annibali S. Comparison of conventional methods and laser-assisted rapid prototyping for manufacturing fixed dental prostheses: An in vitro study. Biomed Res Int 2015;2015:318097.

28. Castillo-Oyagüe R, Osorio R, Osorio E, Sánchez-Aguilera F, Toledano M. The effect of surface treatments on the microroughness of laser-sintered and vacuum-cast base metal alloys for dental prosthetic frameworks. Microsc Res Tech 2012;75: 1206-12.

29. Örtorp A, Jönsson D, Mouhsen A, Vult von Steyern P. The fit of cobalt-chromium three-unit fixed dental prostheses fabricated with four different techniques: a comparative in vitro study. Dent Mater 2011;27:356-63.

30. Xu D, Xiang N, Wei B. The marginal fit of selective laser melting-fabricated metal crowns: an in vitro study. J Prosthet Dent 2014;112:1437-40.

31. Iseri U, Ozkurt Z, Kazazoglu E. Shear bond strengths of veneering porcelain to cast, machined and laser-sintered titanium. Dent Mater J 2011;30:274-80.

32. Xiang N, Xin XZ, Chen J, Wei B. Metal-ceramic bond strength of Co-Cr alloy fabricated by selective laser melting. J Dent 2012;40:453-7.

33. Almeida e Silva JS, Erdelt K, Edelhoff D, Araújo É, Stimmelmayr M, Vieira LC, Güth JF. Marginal and internal fit of four-unit zirconia fixed dental prostheses based on digital and conventional impression techniques. Clin Oral Investig 2014;18:515-23. 